\title{
Stage IIB Small Intestinal Cancer AJCC v7
}

National Cancer Institute

\section{Source}

National Cancer Institute. Stage IIB Small Intestinal Cancer A/CC v7. NCI Thesaurus. Code C87792.

Stage IIB includes: T4, N0, M0. T4: T umor perforates the visceral peritoneum or directly invades other organs or structures (including other loops of small intestine, mesentery, or retroperitoneum more than $2 \mathrm{~cm}$, and abdominal wall by way of serosa; for duodenum only, invasion of pancreas or bile duct). N0: No regional lymph node metastasis. M0: No distant metastasis. (AJCC 7th ed.) 